БЕЛЬКОВ Олег Алексеевич - доктор философских наук, профессор; старший научный сотрудник НИИ военной истории Военной академии Генерального штаба ВС РФ (119330, Россия, г. Москва, Университетский $n$-кт, 14; belkovole@yandex.ru)

\title{
ИСТОРИЯ: НАУКА ИЛИ ИДЕОЛОГИЯ?
}

Аннотация. Статья представляет собой отклик на журнальную публикацию С. Ф. Черняховского «О целях и задачах исторического исследования». Отталкиваясь от сформулированных в ней положений, автор рассуждает о том, зачем и как «писать историю». Черняховский утверждает, что забвение, тем более огульное осуждение прошлого, гибельно для народа. С другой стороны, история как процесс является объектом, а история как наука - инструментом, средством глобальной конкуренции и геополитического соперничества. И потому она всегда пишется в координатах интересов и ценностей социальной группы, с которой идентифицирует себя исследователь.

Ключевые слова: история, историческая наука, исторический факт, функции и дисфункции исторической науки, научность и объективность истории

$\mathrm{O}$ чень интересная и глубокая статья С.Ф. Черняховского опубликована в последнем номере журнала за 2017 г. [Черняховский 2017]. В ней речь идет об извечных вопросах: о том, как «писать историю», как находить свидетельства прошлого и проверять их достоверность, как из множества разнородных фактов составить целостную картину исторического события или процесса, выявить их смысл и донести его до читателя. Эти и другие подобные вопросы ставятся и обсуждаются издавна. И многие большие умы в разное время давали на них ясные и однозначные ответы. Некоторые принципиально важные их мысли приведены в настоящей статье.

С.Ф. Черняховский четко и внятно излагает свое понимание поднятой проблемы, сформулировав его в 11 пунктах. Все предложенные им позиции представляются ясными, понятными, приемлемыми. Полностью принимая их, я не предлагаю другое видение обсуждаемого вопроса, не вступаю с автором в дискуссию. Напротив, хотелось бы привести несколько соображений в поддержку, дополнение и развитие высказанных им идей, расширить аргументы, подтверждающие их актуальность и значимость, в некоторых случаях несколько иначе расставить акценты в их содержании.

Но прежде чем говорить, как «писать историю», следует определиться в том, что есть наука история. Все словари лаконично определяют: история - наука о развитии человеческого общества. Это так. Но данное определение не раскрывает сформулированные Черняховским вопросы сущностного характера: «что и как мы изучаем, говоря, что изучаем историю», в чем смысл и назначение исторической науки - «в выявлении бесконечного множества фактов или в установлении связей между фактами, выявлении закономерностей и законов, действующих в истории».

Дело в том, что история как процесс развития общества знает только одну единицу анализа - событие, факт. История же как наука имеет дело с фактами троякого рода.

1. Исторические факты - действительные явления, процессы, имевшие место в определенных времени и пространстве. Причем речь идет не только о материальных, физических событиях, но и о духовных образованиях - состоянии общественного сознания, характерных для него интересах, страстях, идеях, верованиях, заблуждениях, мифах, которые выступали мотивами, движущей силой деятельности людей. И призвание исторической науки как раз состоит в выявлении и установлении этих фактов.

2. Источниковедческие факты - сведения, фиксированные в различных 
источниках - вещественных остатках материальной культуры, летописях, различного рода документах, воспоминаниях и т.д. Каждый из них и все они вместе составляют разрозненные фрагменты прошлого. Ни один из них не обладает исчерпывающей полнотой и абсолютной точностью. К тому же если первые бесстрастны, то о письменных источниках истории этого сказать нельзя. Их аутентичность и достоверность определяет исследователь.

3. Научно-исторические факты - теоретическая, мыслительная реконструкция прошлого, осуществляемая исследователем. Факты этого рода, являющиеся продуктом интеллектуального труда, как раз и образуют ткань науки истории. Как пишет В.С. Библер, для исторической науки факты - это образы факта, высказывания о факте, теоретическая конструкция [Библер 2007]. Но именно они составляют содержание научных монографий, мемуаров и исторических романов, школьных и вузовских учебников.

Наука история представляет собой органический синтез фактов всех трех родов: исследование утрачивает статус науки, если игнорирует, отказывается признавать это триединство. Сведе́ние его к одному из них превращает науку в бессистемный и бессвязный набор хроник либо в нарратив - беллетризованный пересказ имеющейся информации об описываемых автором событиях в личностно осмысленной им связи и последовательности, либо в абстрагированное от событийной стороны исторического процесса историософское осмысление и раскрытие исторических закономерностей.

Иными словами, факт и высказывание о факте - не аутентичные феномены. Высказывание о факте всегда субъективировано. Историю пишут люди, не свободные от личных пристрастий, непредумышленных ошибок, а порой и корыстных расчетов. Далекие от правды жизни сведения в ней могут быть следствием и добросовестного заблуждения, и злого умысла.

В этой связи встает вопрос, о котором Черняховский говорит, не останавливаясь на его дискуссионности, подчеркивая «политическое значение развития классической исторической науки». Я имею в виду взаимосвязь истории и идеологии, истории и политики.

Господствующий (модный, популярный) ныне мейнстрим исходит из необходимости деидеологизации и деполитизации едва ли не каждой сферы общества и каждого вида человеческой деятельности, в т.ч. и истории. Многие авторы, касающиеся этой темы, объясняя и обосновывая объективность исторической науки, пишут, как об очевидной данности, что она деидеологизирована и деполитизирована. На высоком официальном уровне говорится об этом не как о данности, а как об императиве.

«Политики, оставьте историю историкам. Перестаньте играть в историческую политику», - говорит, например, заместитель генерального директора Музея Москвы Никита Соколов ${ }^{1}$. А в Концепции внешней политики РФ в редакции 2013 г. говорилось, что Россия видит свои задачи в том, чтобы способствовать деполитизации исторических дискуссий, переводу их исключительно в академическое русло.

Конечно, люди вольны призывать вывести историю за рамки политики. Но не получается оставить историю историкам.

Во-первых, историей интересуются, ее изучают не только профессионалыисследователи, но и огромная масса людей, не входящих в научное сообщество историков: создатели исторических романов и кинофильмов, любителикраеведы, участники движения исторической реконструкции, другие группы населения, для которых увлечение историей является хобби. Во-вторых, исто-

${ }^{1}$ https://www.kommersant.ru/doc/2746275 (проверено 07.02.2018). 
рия стала предметом публицистики. В истории многое определяет расстановка акцентов. И публицистика, равно как кино и шире - искусство, расставляя эти акценты, наряду с академической наукой формирует исторический дискурс всего общества.

Кстати сказать, и в среде профессиональных историков наличествуют полярные взгляды на исторические события; специалисты-историки вовсе не единодушны в объяснении и оценке фактов и фигур прошлого. И дискуссии, развертывающиеся в академическом русле, не утрачивают политическую заостренность. К тому же какая разница обществу, получающему политическую трактовку тех или иных событий, являются их авторами политики, академики или публицисты? Различные вбросы так называемой альтернативной истории одинаково пагубны независимо от того, в какой среде они разрабатываются. В Основах государственной культурной политики (утв. указом Президента РФ от 24 декабря 2014 г. № 808) в числе пяти наиболее опасных для будущего России проявлений гуманитарного кризиса названы «деформация исторической памяти, негативная оценка значительных периодов отечественной истории, распространение ложного представления об исторической отсталости России».

История не должна и не может быть деполитизированной. О связи истории и политики пишут многие. Тезис о политическом значении исторической науки следует проговорить до конца. Политическое значение, т.е. смысл, содержание и роль исторической науки, состоит в следующем.

Во-первых, история формирует историческое и, следовательно, национальное самосознание народа, его идентичность и отношение к государству и существующей в нем власти.

Во-вторых, история дает, вернее, в ней ищут и находят материал для обоснования определенных интересов, ценностей, идеалов. Не история и ее трактовки вторгаются в область сегодняшних политических интересов, а политические субъекты привлекают историю для обоснования и оправдания своих целей и действий.

В-третьих, история служит основой для выработки актуальной политики, обеспечивает жизнеспособность и жизнестойкость социума. Для конкретного исследователя изучение истории может быть удовлетворением собственной любознательности. Но социальная востребованность науки истории, ее становление и развитие вызываются отнюдь не психологией, а соображениями мировоззренческого (раньше говорили - идеологического) и политико-практического характера.

«Мы вопрошаем и допрашиваем прошедшее, - писал В.Г. Белинский, чтобы оно объяснило нам наше настоящее и намекнуло о нашем будущем». «Задача историка, - констатировал А.А. Свечин, - заставить памятники прошлого отвечать на вопросы современности... Мы же от историка требуем смелую, свежую и непосредственно касающуюся нас мысль, даже если дело идет о древней Греции и Риме» [Постижение военного... 1999: 486-487]. Именно об этом пишет Черняховский, отмечая, что верное понимание уроков прошлого является условием эффективности действий в настоящем и будущем.

В-четвертых, история как процесс является объектом, а история как наука инструментом, средством глобальной конкуренции и геополитического соперничества. Специалисты отмечают, что в последние 20 лет в Европе реальностью стала историческая политика - использование истории, исторических фактов, определенным образом интерпретированных, для достижения сиюминутных конъюнктурных политических целей ${ }^{1}$.

\footnotetext{
$1^{1}$ https://www.kommersant.ru/doc/2746275 (проверено 07.02.2018).
} 
B-пятых, история как наука не просто описывает процессы и события, имевшие место в прошлом. Ее назначение - выработка систем ценностей, обоснование того, что должно быть и чего не должно быть в социальном мире. «Историки, писал Н.И. Кареев, - и не думая об этом, все-таки продолжают судить и рядить... Одни развенчивают, снимают с пьедесталов, записывают на черную доску тех, кому кланялось человечество; другие занимаются реабилитацией, возвышением, прославлением... Где история, там и суд, но часто суд односторонний, пристрастный, неправый... Прогоните его в явной форме, он вотрется к вам невидимкой: в выборе, освещении предмета...» [Кареев 1991: 26]. Как констатировал французский поэт и политический деятель А. Ламартин, «беспристрастие истории - не безразличие зеркала, которое только отражает предметы; это - беспристрастие судьи, который смотрит, слушает и произносит приговор» 1 .

В полном соответствии с этим и Черняховский подчеркивает, что «осмысление и оценка исторического события не может производиться без учета степени его соответствия тем или иным интересам».

В той мере, в какой историческая наука содержит оценку политических процессов с определенных позиций, т.е. содержит различные предубеждения, она является идеологией. Так я подошел к вопросу, вынесенному в заглавие статьи.

Давайте определимся с понятием. Что такое идеология? Среди многих определений идеологии отправным, базовым является ее понимание как системы идей и взглядов, выражающих коренные интересы какой-либо социальной группы. Но ведь и народ государства представляет собой такую группу. «Государство, - писал К. Шмитт, - есть политический статус народа, организованного в территориальной замкнутости» [Шмитт 2011: 17]. При отсутствии такой системы происходит атомизация общества - распад традиционных связей в обществе, социальное разобщение, появление изолированных индивидов, социальные связи которых носят безличный характер; народ вырождается в население, для которого судьба государства, в котором оно живет, в лучшем случае безразлична.

История как наука не просто раскрывает процессы и события, имевшие место в прошлом. Она устанавливает их причины и последствия. Она описывает и осмысливает их сквозь призму социально-групповых (государственных, классовых, этнических, конфессиональных и т.д.) интересов.

Выявляя и освещая явления и процессы прошлого, историк оценивает их соответствие (несоответствие) определенному идеалу в координатах истины и заблуждения, добра и зла, прекрасного и безобразного, святости и греховности, законности и преступности, справедливости, гуманизма.

Разработка любой исторической темы проводится в координатах определенной системы. Соглашаясь с этим, мы признаем, что история - наука идеологизированная. Здесь мы вступаем в известное противоречие с конституционной нормой, устанавливающей, что в России нет обязательной или государственной идеологии. Наверное, правильно, что в демократическом и плюралистическом обществе обязательной идеологии не должно быть. Но это предполагает наличие множества идеологий. В их ряду не может не быть и государственной, вернее, государственнической идеологии.

Государственной, т.е. государством разрабатываемой, идеологии, возможно, и не должно быть, поскольку она по определению окажется обязательной. Но государственнической идеологии, отражающей интересы, ценности, идеалы государства, в т.ч. заявленные в Конституции РФ (идея суверенитета, парламентаризма, социального равенства, прав и свобод человека, идея защиты

\footnotetext{
${ }^{1}$ Альфонс де Ламартин. Цитаты. Доступ: https://tsitaty.com/\%D0\%B0\%D0\%B2\%D1\%82\%D0\%BE\% D1\%80/\%D0\%B0\%D0\%BB\%D1\%8C\%D1\%84\%D0\%BE\%D0\%BD\%D1\%81-\%D0\%B4\%D0\%B5-\%D0\% BB\%D0\%B0\%D0\%BC\%D0\%B0\%D1\%80\%D1\%82\%D0\%B8\%D0\%BD
} 
Отечества как долга и обязанности гражданина и т.д.), не может не быть. И государство по определению должно поддерживать такую идеологию и способствовать ее распространению. Так, В.В. Путин, выступая против «казенной идеологии», подчеркнул, что «государство обязано и имеет право и свои усилия, и свои ресурсы направлять <...> на формирование мировоззрения, скрепляющего нацию» 1 .

Декларируемый отказ от идеологии вовсе не делает общество и разные группы в нем деидеологизированными. Просто одни идеологии публично осуждаются и отвергаются, другие становятся малозаметными, маргинальными, третьи выступают под чужим, якобы не идеологическим флагом.

История по определению наука тенденциозная. Тенденциозность исторического исследования выражается в приверженности автора определенной идее и может иметь двоякую форму.

С одной стороны, она проявляется в пристрастном или предвзятом, необъективном, одностороннем истолковании исследуемой темы.

Нельзя не видеть, что есть так называемые историки, которые родную историю видят и трактуют не как верные и вдумчивые сыны отечества, но как не знающие ни милосердия и сострадания, ни естественной для нормального человека снисходительности к собственным слабостям, ни даже широко популяризуемой ныне толерантности. Их усилиями создается так называемая альтернативная история. Она представляет собой исследования, сбор фактов и представление какого-либо события, явления, государства, народа, личности в таком виде, который кардинальным образом отличается от традиционной (академической) истории. Часто «альтернативщики» истории преследуют коммерческие, политические цели. При этом результат в большинстве случаев разительно отличается от официальной истории. Разница в подходах к анализу исторических событий и артефактов позволяет альтернативной истории «доказывать», что довольно много положений официальной истории не более чем миф, а иногда и подлог. Такая тенденциозность ничего общего с наукой не имеет.

Порою специально оговаривается, что неправильно, тенденциозно описанная и изученная история никого, никогда и ничему не научит. Более того, она вредна, ибо самое худшее для общественно-политической практики это ориентировка на искаженный исторический опыт ${ }^{2}$. Однако это не так. Альтернативная история тоже учит и воспитывает. Но ее ученики и последователи становятся ненавистниками России.

С другой стороны, речь идет о последовательном проведении определенных идей, тенденций. Имея в виду именно эту сторону, М.Е. Салтыков-Щедрин объяснял громадное воспитательное значение художественных произведений тех писателей, которые были тенденциозны тем, что они беседовали с читателями не о сновидениях, а раскрывали перед ними ту жизненную разрозненность и смуту, под гнетом которых страдало и страдает человечество. «Разрозненность, случайность, вялость, - отмечал он, - вот характеристические качества произведений, отвергающих так называемую тенденциозность, и не выкупятся эти недостатки никакими подробностями, как бы искусно и ловко они ни были составлены» $^{3}$. Оценку Салтыков-Щедрина в полной мере можно отнести и к историческим работам.

Как уже говорилось, Черняховский пишет, что история должна быть позитивной: «...основная задача восстановления целостного и позитивного виде-

\footnotetext{
1 Путин В.В. Россия: национальный вопрос. - Независимая газета. 2012. 23 янв.

2 https://touch.otvet.mail.ru/question/84592128

3 Салтыков-Щедрин М. Е. Снопы. 1871.
} 
ния истории - рассмотрение истории России/СССР с позиции позитивной истории». Согласимся и признаем, что в позитивности и состоит ее тенденциозность. Позитивность не означает, что исследователь отбирает только положительные факты и фигуры истории, умалчивая о грехах, горестях и бедах России. Нет, историю надо писать объективно и честно. «Первый закон истории, - писал М.Т. Цицерон, - бояться какой бы то ни было лжи, а затем - не бояться какой бы то ни было правды» 1 . Честный историк должен говорить и о тех несправедливостях, виновником которых была Россия, и о тех, что творились по отношению к ней.

Объективность как важнейший методологический принцип науки истории предполагает точное воспроизведение событий, явлений и фигур, какими они являлись в действительности. Никаких домыслов, предположений, неопределенности или амбивалентности в описании событийной стороны не должно быть. При этом в анализ включаются все известные факты без каких-либо умолчаний независимо от отношения к ним. Именно и только хроника - перечень и описание событий в их временной последовательности - составляет объективное содержание исторической науки.

Но в объяснении выявленных и исследуемых фактов, отношении к ним, в оценке их причинно-следственных связей, значения и последствий объективность уступает место тенденциозности (в советское время говорили «партийности», понимая под ней соответствие классовым интересам, партийным установкам). Еще раз процитирую Черняховского: «Самое странное, что может быть, - это отказ от принятия тех или иных критериев оценки исторических событий с позиций тех или иных социальных интересов, поскольку значение события в принципе не может быть определено вне вопроса о том, относительно чего и для кого значение этого события определяется».

Всякий ученый придерживается ценностных установок и идеалов определенной социальной, этнической, религиозной и т.д. группы, и в силу этого его взгляды определенным образом идеологизированы и политизированы. Так, не по партийной принадлежности, а по жизненной позиции либерал и консерватор, монархист и республиканец, социалист и националист одни и те же факты воспринимают и оценивают по-разному. «Чтобы писать историю достойным образом, - иронизировал французский лексикограф Пьер Буаст, - надо забыть о своей вере, своем отечестве, своей партии» [Борохов 2003: 220]. Нужно ли говорить, что такое на деле невозможно? В этом смысле предельно категоричен был Карл Поппер: «Объективность и непредвзятость на уровне конкретного ученого практически недостижимы» [Дэникен 2006].

O том, чем должен руководствоваться автор труда по национальной истории, Карамзин высказывался так: «Из всех литературных произведений народа изложение истории его судьбы более всего должно вызывать интерес и менее всего может иметь общий, не строго национальный характер. Историк должен ликовать и горевать со своим народом. Он не должен, руководимый пристрастием, искажать факты, преувеличивать счастье и умалять в своем повествовании бедствия; он должен быть, прежде всего, правдив; но может, даже должен все неприятное, все позорное в истории своего народа передавать с грустью, а о том, что приносит честь, о победах, о цветущем состоянии говорить с радостью и энтузиазмом. Только таким образом, может, он сделается национальным бытописателем, чем, прежде всего, должен быть историк»².

\footnotetext{
1 Высказывания, изречения, афоризмы Марка Туллия Цицерона. Доступ: http://best-words.ru/ ciceron-14/

2 Русская старина. 1890. № 9. С. 453.
} 
Таким образом, отвечая на поставленный в названии статьи вопрос, скажу так: история - наука, но наука идеологизированная.

\section{Список литературы}

Библер В.С. 2007. Исторический факт как фрагмент действительности. Библер и вокруг: сайт. Доступ: bibler.ru/bis_istor_fakt.html (проверено 27.11.2015). Борохов Э. 2003. Энииклопедия афоризмов. Мысль в слове. М.: АСТ. 720 с.

Дэникен Э., фон. 2006. Каменный век был иным... Будущее, скрытое в загадках прошлого. М.: Эксмо. 288 с. Доступ: http://vikidalka.ru/1-73680.html

Кареев Н.И. 1991. Суд над историей. - Рубеж. № 1. С. 6-32.

Постижение военного искусства. Идейное наследие А. Свечина. 1999. М.: Русский путь. 696 с.

Черняховский С.Ф. 2017. О целях и задачах исторического исследования. Власть. № 12. С. 7-10.

Шмитт К. 2011. Понятие политического. М.: НИЦ «Инженер». 291 с.

BEL'KOV Oleg Alekseevich, Dr.Sci. (Philos.), Professor; Senior Researcher of the Research Institute of Military History, Military Academy of the General Staff of the Armed Forces of the Russian Federation (14 Universitetsky Ave, Moscow, Russia,119330; belkovoleg@umail.ru)

\section{HISTORY: SCIENCE OR IDEOLOGY?}

Abstract. The article represents a response to the journal publication of S.F. Chernyakhovsky «About purposes and problems of historical research". The author, starting from the provisions formulated in it, discusses why and how to "write a history». S.F. Chernyakhovsky, on the one hand, argues that oblivion, especially the indiscriminate condemnation of the past is disastrous for the people. On the other hand, history as a process is an object, and history as a science is an instrument, a means of global competition and geopolitical rivalry. That is why history always is written in the coordinates of the interests and values of the social group with which the researcher identifies himself.

Keywords: history, historical science, historical fact, functions and dysfunction of historical science, scientificity and objectivity of history 